|| Print ISSN: 2589-7837 || Online ISSN: 2581-3935 ||

International Journal of Medical Science and Diagnosis Research (IJMSDR)

Available Online at www.ijmsdr.com

NLM (National Library of Medicine ID: 101738824)

Original Research Article

Volume 6, Issue 2; February: 2022; Page No. 12-19

\title{
To Study the Prevalence of Vitamin D Deficiency in Third Trimester and Feto-Maternal Outcome. \\ Dr. Sheetal Dagar ${ }^{1}$, Dr. Monika Gupta ${ }^{2}$, Dr. Monika Jindal' ${ }^{3}$, Dr. Santosh Minhas ${ }^{4}$, Dr. Srishti Aggarwal ${ }^{5}$ \\ 1,2,3,4,5 MMMC \& H, Solan
}

\section{Conflicts of Interest: Nil}

Corresponding author: Dr. Sheetal Dagar

DOI: https://doi.org/10.32553/ijmsdr.v6i2.913

\section{Abstract:}

Aim: To estimate the prevalence of vitamin D deficiency in third trimester and its correlation with feto-maternal outcome

Material and Methods: Present study was conducted 200 pregnant women who were admitted to the labor room in the third trimester in the department of Obstetrics \&amp; Gynecology of Maharishi Markandeshwar Medical College and Hospital, Solan (H.P.) for delivery after fulfilling the inclusion \&amp; exclusion criteria. Detailed history including complete demographic information, past medical history, dietary history, previous menstrual \&amp; obstetric history, any antenatal complications. Delivery details including mode of delivery, birth weight and APGAR scores were recorded on the proforma. Serum vitamin $\mathrm{D}$ was estimated from the maternal blood sample. Vitamin D deficiency was defined as $25(\mathrm{OH}) \mathrm{D}$ levels in blood less than $20 \mathrm{ng} / \mathrm{ml}$, and insufficiency of vitamin D was defined as 25(OH) D levels between 20-30 $\mathrm{ng} / \mathrm{ml}$.

Results: In this study, there was a high prevalence of vitamin D deficiency (93.5\%) in the pregnant women though there was no significant difference in socio-demographic factors in the deficient and non-deficient group. Present study showed that the proportion of vitamin D deficient pregnant women having maternal complications and NICU admission was statistically significant as compared to the non-deficient group $(\mathrm{p}=0.0109)$ and $(\mathrm{p}=0.0384)$ respectively.

Conclusion: Maternal complications, increased cesarean section rate and NICU admission were more associated with hypovitaminosis D but any causal relationship between vitamin D deficiency and pregnancy complications was not found in this study design. We propose that vitamin D supplementation is simple and economical, and hence we should incorporate vitamin D testing, increase its awareness and treat its deficiency in adolescence, pre-conceptional period or 1 st trimester to avoid maternal complications and poor fetal outcome.

Keywords: Vitamin D Deficiency, Third trimester, Fetal outcome, Maternal outcomex 


\section{Introduction:}

Pregnancy increases the demand for vitamins and microelements, including vitamin D. Adaptation of calcium metabolism to pregnancy involve doubling of calcitriol synthesis that necessitates an adequate supply of vitamin D. While only less than $10 \%$ of vitamin $\mathrm{D}$ is derived from dietary sources, skin synthesis, requiring ultraviolet (UV) radiation, remains the main source of vitamin D. Furthermore, the amount of vitamin $\mathrm{D}$ in most multivitamin supplements designed for pregnant women is not sufficient, while not all pregnant women declare taking those supplements. Maternal vitamin D deficiency during pregnancy may be associated with adverse pregnancy outcomes, such as miscarriage, preeclampsia, preterm birth, gestational diabetes, and bacterial vaginosis. ${ }^{1}$

Despite being a tropical country and adequate sunshine throughout the year, studies have shown widespread prevalence of hypovitaminosis D in India and reason for this can be less outdoor activity, vegetarian diet, wearing of more covered clothing, and no policy of fortification of food items with vitamin $\mathrm{D}$. There paradox may be partly explained by the many prevalent social and cultural practices in India that preclude adequate exposure of adolescent girls and young women to sunshine. Newly married females are expected to cover themselves even more and are discouraged from outdoor activity. Increasing urbanization \& exposure to computer and games has resulted in poor outdoor activity and greater pollution, coupled with skin pigment, may further compound this problem. ${ }^{2}$

Identifying Vitamin D deficiency by the circulating concentration of $25(\mathrm{OH}) \mathrm{D}$, the indicator of nutritional Vitamin D status. There is no consensus about the optimal 25 $(\mathrm{OH}) \mathrm{D}$ level, but many experts accept a range $75 \mathrm{nmol} / \mathrm{L}(>30 \mathrm{ng} / \mathrm{ml})$ as optimal and serum Vitamin D levels below $50 \mathrm{nmol} / \mathrm{L}$ (20ng/ml) represent deficiency. Sufficiency
- $25(\mathrm{OH}) \mathrm{D}>30 \mathrm{ng} / \mathrm{ml}$, Insufficiency -
$25(\mathrm{OH}) 20-30 \mathrm{ng} / \mathrm{ml}$ and Deficiency -
$25(\mathrm{OH})<20 \mathrm{ng} / \mathrm{ml}^{3}$

Material and Methods

Present study is a hospital based analytical, cross sectional study conducted in the Department of Obstetrics and Gynecology Maharishi Markandeshwar Medical College and Hospital, Kumarhatti, Solan, Himachal Pradesh over a period of 18 months in which a total 200 pregnant women who were admitted to the labor room in the third trimester for delivery were included in the study after befitting inclusion and exclusion criteria.

\section{Inclusion Criteria:}

1. Gestational age 28 weeks and above

2. Patients with singleton pregnancy

3. Willing for participation and giving consent

\section{Exclusion Criteria:}

Known history or evidence of:

1. Overt thyroid, parathyroid or adrenal diseases

2. Type 1 diabetes mellitus

3. Malabsorption, hepatic or renal failure

4. Metabolic bone disease

5. Multiple gestation

6. Pregnancy of $<28$ weeks

Detailed history was collected including complete demographic information, past medical history, dietary history, previous menstrual \& obstetric history, any antenatal complications. Delivery details including mode of delivery, birth weight, APGAR scores and NICU admission were recorded on the proforma. Serum vitamin D was estimated from the maternal blood sample. Sample collection: Maternal blood (2 ml) was drawn at the time of delivery for estimation of $25(\mathrm{OH})$ D to diagnose hypovitaminosis D. Serum was separated 
from collected samples, and they were stored at 2 to 8 degrees celsius till analysis. Vitamin D was analyzed by the chemiluminescence method on Advia Centaur XP. Vitamin D deficiency was defined as $25(\mathrm{OH})$ D levels in blood less than $20 \mathrm{ng} / \mathrm{ml}$, and insufficiency of vitamin $\mathrm{D}$ was defined as $25(\mathrm{OH}) \mathrm{D}$ levels between 20-30 ng/ml. Other investigations like liver function test (LFT), renal function test (RFT), serum calcium were optional and were done whenever required.

\section{Results}

Data of a total of 200 patients was taken after filling inclusion and exclusion criteria and were divided into two groups deficient (group 1) and non-deficient groups (group 2) based on the vitamin D levels of $20 \mathrm{ng} / \mathrm{ml}$ as cut off value. Non deficient groups include sufficient $(>30 \mathrm{ng} / \mathrm{ml})$ and insufficient $(20-30 \mathrm{ng} / \mathrm{ml})$ vitamin D levels.

Table 1: Socio-demographic factors

\begin{tabular}{|c|c|c|}
\hline Variables & Number $n=200$ & Percentage \\
\hline \multicolumn{3}{|l|}{ AGE } \\
\hline 19-24 years & 63 & $31.5 \%$ \\
\hline $25-34$ years & 124 & $62 \%$ \\
\hline$>35$ years & 13 & $6.5 \%$ \\
\hline \multicolumn{3}{|l|}{ BMI } \\
\hline $18.5-24.9$ & 26 & $13 \%$ \\
\hline $25-29.9$ & 166 & $83 \%$ \\
\hline 30 and above & 8 & $4 \%$ \\
\hline \multicolumn{3}{|l|}{ EDUCATION } \\
\hline Illiterate & 3 & $1.5 \%$ \\
\hline Primary school & 5 & $2.5 \%$ \\
\hline Middle school & 5 & $2.5 \%$ \\
\hline High school & 18 & $9 \%$ \\
\hline Higher secondary & 92 & $46 \%$ \\
\hline Graduate & 77 & $38.5 \%$ \\
\hline \multicolumn{3}{|l|}{ OCCUPATION } \\
\hline Homemaker & 139 & $69.5 \%$ \\
\hline Physical laborer/Farmer & 24 & $12 \%$ \\
\hline Office work & 37 & $18.5 \%$ \\
\hline \multicolumn{3}{|l|}{ RESIDENCE } \\
\hline Rural & 62 & $31 \%$ \\
\hline Urban & 138 & $69 \%$ \\
\hline \multicolumn{3}{|c|}{ SOCIOECONOMIC STATUS* } \\
\hline Upper class & 4 & $2 \%$ \\
\hline Upper middle & 34 & $17 \%$ \\
\hline Lower Middle & 107 & $53.5 \%$ \\
\hline Upper lower & 40 & $20 \%$ \\
\hline Lower & 15 & $7.5 \%$ \\
\hline
\end{tabular}

* According to modified Kuppuswamy scale 
Table 2: Prevalence of vitamin D deficiency in the study group

\begin{tabular}{|l|l|l|}
\hline Vitamin D levels (in ng/ml) & Number & Percentage \\
\hline Deficient (Less than 20) & 187 & 93.5 \\
\hline Insufficient (20-30) & 5 & 2.5 \\
\hline Sufficient (>30) & 8 & 4 \\
\hline Grand Total & 200 & 100 \\
\hline
\end{tabular}

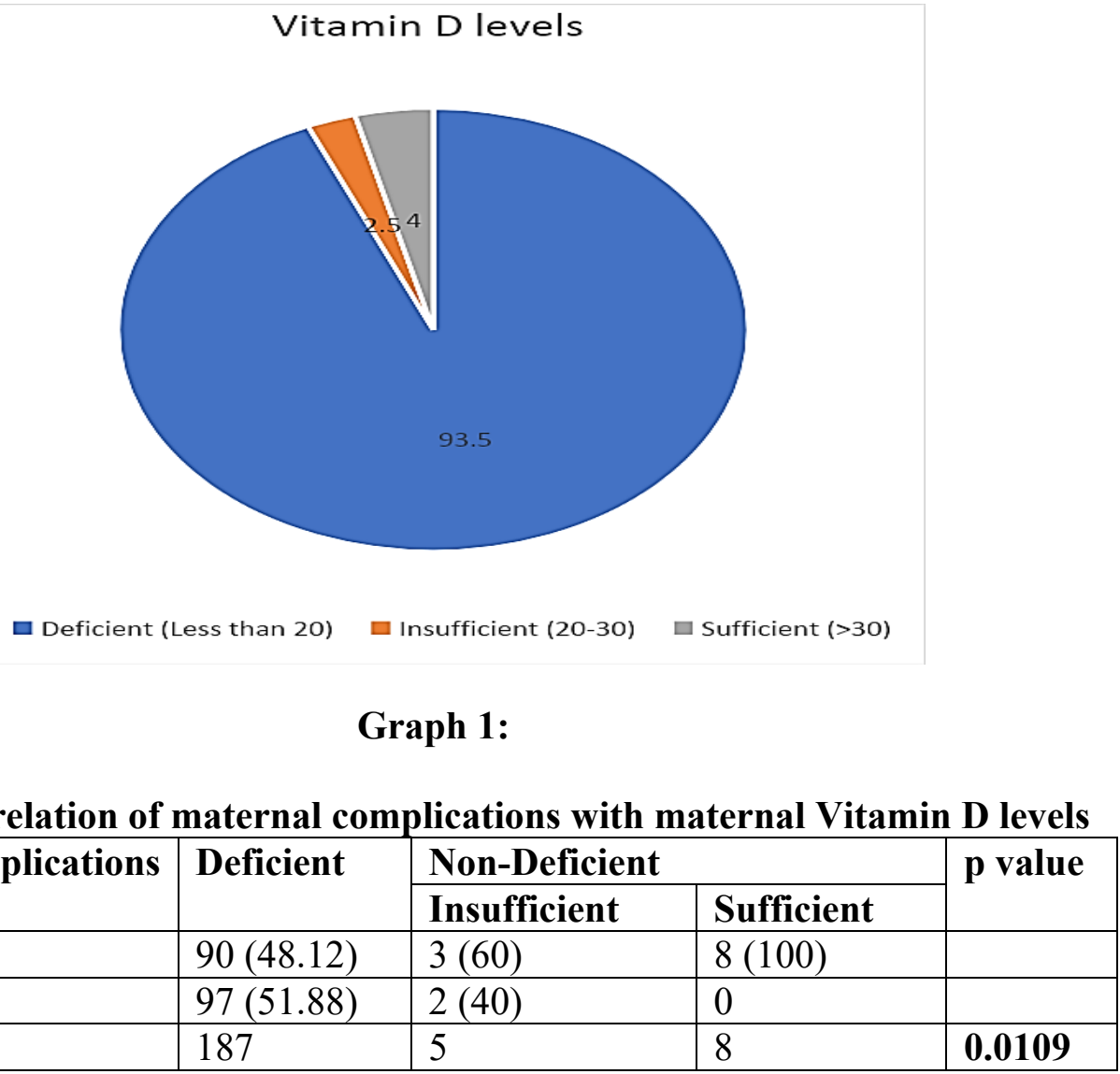

Table 3: Correlation of maternal complications with maternal Vitamin D levels

\begin{tabular}{|l|l|l|l|l|}
\hline Maternal complications & \multirow{2}{*}{ Deficient } & \multicolumn{2}{|l|}{ Non-Deficient } & \multirow{2}{*}{ p value } \\
\cline { 3 - 4 } & & Insufficient & Sufficient & \\
\hline No & $90(48.12)$ & $3(60)$ & $8(100)$ & \\
\hline Yes & $97(51.88)$ & $2(40)$ & 0 & \\
\hline Grand Total & 187 & 5 & 8 & $\mathbf{0 . 0 1 0 9}$ \\
\hline
\end{tabular}

Table 4: Distribution of maternal complications

\begin{tabular}{|l|l|l|}
\hline Maternal complications & Deficient $(\mathbf{n = 9 7})$ & Insufficient $(\mathbf{n}=\mathbf{2})$ \\
\hline Preterm & $45(46.39)$ & $2(100)$ \\
\hline Anemia & $25(25.77)$ & 0 \\
\hline GDM & $15(15.46)$ & 0 \\
\hline Hypothyroid & $15(15.46)$ & 0 \\
\hline Cholestasis & $15(15.46)$ & 0 \\
\hline Preeclampsia & $5(5.15)$ & 0 \\
\hline
\end{tabular}

Table 5: Correlation of Mode of delivery with maternal Vitamin D levels

\begin{tabular}{|l|l|l|l|l|}
\hline \multirow{2}{*}{ Mode of delivery } & \multirow{2}{*}{ Deficient } & \multicolumn{2}{|l|}{ Non-Deficient } & \multirow{2}{*}{ p value } \\
\cline { 3 - 4 } & & Insufficient & Sufficient & \\
\hline LSCS & $72(38.50)$ & $3(60)$ & 0 & \\
\hline NVD & $115(61.50)$ & $2(40)$ & $8(100)$ & \\
\hline Grand Total & 187 & 5 & 8 & 0.2666 \\
\hline
\end{tabular}


Table 6: Distribution of preterm birth and maternal Vitamin D levels

\begin{tabular}{|l|l|l|l|l|}
\hline Preterm birth & Deficient & Non-Deficient & p value \\
\cline { 3 - 4 } & & Insufficient & Sufficient & \\
\hline $28-31+6$ weeks & $2(4.44)$ & 0 & 0 & \\
\hline $32-33+6$ weeks & $5(11.11)$ & 0 & 0 & \\
\hline $34-36+6$ weeks & $38(84.44)$ & $2(100)$ & 0 & \\
\hline Total & 45 & 2 & 0 & 0.8330 \\
\hline
\end{tabular}

Table 7: Correlation of birth weight with maternal Vitamin D levels

\begin{tabular}{|l|l|l|l|l|}
\hline \multirow{2}{*}{ Birth weight } & \multirow{2}{*}{ Deficient } & \multicolumn{2}{|l|}{ Non-Deficient } & \multirow{2}{*}{ p value } \\
\cline { 3 - 4 } & & Insufficient & Sufficient & \\
\hline$\geq 2.5 \mathrm{~kg}$ & $137(73.26)$ & $3(60)$ & $8(100)$ & \\
\hline $1.5-<2.5 \mathrm{~kg}$ & $47(25.13)$ & $2(40)$ & 0 & \\
\hline $1-<1.5 \mathrm{~kg}$ & $3(1.60)$ & 0 & 0 & \\
\hline Grand Total & 187 & 5 & 8 & 0.6402 \\
\hline
\end{tabular}

Table 8: Correlation of APGAR score with maternal Vitamin D levels

\begin{tabular}{|l|l|l|l|l|}
\hline APGAR & \multirow{2}{*}{$\begin{array}{l}\text { Deficient } \\
\mathbf{n}=\mathbf{1 8 7}\end{array}$} & Non-Deficient & \multirow{2}{*}{ v value } \\
\cline { 3 - 4 } & $181(96.79)$ & $4(80)$ & $8(100)$ & \\
\hline No & $6(3.21)$ & $1(20)$ & 0 & 0.3950 \\
\hline Yes & $185(98.94)$ & $5(100)$ & $8(100)$ & 0.7078 \\
\hline No & $2(1.06)$ & 0 & 0 & \\
\hline Yes & & &
\end{tabular}

Table 9: Correlation of NICU admission with maternal Vitamin D levels

\begin{tabular}{|l|l|l|l|l|}
\hline NICU admission & \multirow{2}{*}{ Deficient } & Non-Deficient & \multirow{2}{*}{ p value } \\
\cline { 3 - 4 } & & Insufficient & Sufficient & \\
\hline No & $120(64.17)$ & $4(80)$ & $8(100)$ & \\
\hline Yes & $67(35.83)$ & $1(20)$ & 0 & \\
\hline Grand Total & 187 & 5 & 8 & $\mathbf{0 . 0 3 8 4}$ \\
\hline
\end{tabular}

Table 10: Reason for NICU admission

\begin{tabular}{|l|l|l|}
\hline Reason for NICU admission & Number & Percentage \\
\hline Transient Tachypnoea of newborn & 19 & 27.9 \\
\hline Respiratory Distress Syndrome & 14 & 20.6 \\
\hline Neonatal Hyperbilirubinemia & 10 & 14.7 \\
\hline Neonatal Sepsis & 7 & 10.3 \\
\hline Meconium Aspiration Syndrome & 5 & 7.4 \\
\hline Feed Intolerance & 4 & 5.9 \\
\hline Hypoglycemia & 3 & 4.4 \\
\hline Perinatal Asphyxia & 2 & 2.9 \\
\hline Pneumonia & 2 & 2.9 \\
\hline Hypothermia & 2 & 2.9 \\
\hline Grand Total & 68 & 100.00 \\
\hline
\end{tabular}


TABLE 1: Most of the subjects in the study were under the age of 25-34 years (124, $62 \%$ ). The mean age was $26.95 \pm 4.53$ years. The range of age for the study was $19-41$ years. BMI of females was between 25 to $29.90 \mathrm{~kg} / \mathrm{m} 2$ (166, 83\%). The mean \pm SD was $26.87 \pm 1.95 \mathrm{~kg} / \mathrm{m} 2$. Most of the subjects in the study were literate up to senior secondary level ( $12^{\text {th }}$ standard) (92, $46 \%)$. Seventy-seven subjects $(38.5 \%)$ in the study had graduate degrees while 18 patients $(9 \%)$ had higher secondary education $\left(10^{\text {th }}\right.$ standard $)$. Majority were homemakers $(139,69.5 \%)$, who worked both indoor and outdoor, 37 (18.5\%) patients did indoor office work, 24 (12\%) patients worked in fields and construction sites as laborers and farmers. $69 \%$ females belonged to the urban areas and most of the pregnant women in the study were from lower middle class $(107,53.5 \%)$ according to the modified Kuppuswamy scale.

TABLE 2: It was observed that most of the subjects were deficient (Less than 20 $\mathrm{ng} / \mathrm{ml})$ in terms of vitamin D levels (187, $93.50 \%)$. Only 8 (4\%) pregnant women had sufficient levels $(>30 \mathrm{ng} / \mathrm{ml})$ of vitamin D. Five pregnant women had vitamin $\mathrm{D}$ levels between 20-30 which falls in the category of insufficient vitamin D levels. The average vitamin D levels in the study were $12.63 \pm 5.95 \mathrm{ng} / \mathrm{ml}$ with a range of 4.20 to $36.50 \mathrm{ng} / \mathrm{ml}$.

TABLE 3: Almost half of the subjects (99, $48.12 \%$ ) had one or more maternal complications during pregnancy. All the subjects with sufficient vitamin D levels had no maternal complications. The proportion of pregnant women with maternal complications was higher in the deficient and insufficient group. The difference was statistically significant $(\mathbf{p}=\mathbf{0 . 0 1 0 9})$.

TABLE 4: The proportion of subjects with preterm delivery, anemia, hypothyroidism, GDM, cholestasis and pre-eclampsia was higher in the deficient and insufficient group of subjects. The difference was not significant statistically for any of these parameters though complications like preterm labor and anemia were highly prevalent.

TABLE 5: Normal vaginal delivery was seen in 125 pregnant women. 75(37.5\%) subjects underwent LSCS, most of them had to undergo emergency LSCS $(57,76 \%)$ while 18 subjects underwent elective LSCS (24\%). Out of 75 subjects of LSCS (96\%) were from the deficient group. All the 8 subjects who had sufficient vitamin D levels delivered vaginally. No statistical significance was found between the mode of delivery and vitamin D levels $(p=0.2666)$.

TABLE 6: 47 babies were preterm delivery out of which $(95.7 \%)$ patients belong to the deficient group. Among all, the majority of babies were late preterm delivery $34-36+6$ weeks $(85.1 \%)$, out of which 38 (84.44\%) babies belong to the deficient group $(\mathrm{p}=0.8330)$. There was no preterm birth in subjects with sufficient vitamin D levels.

TABLE 7: The average birth weight was $2.72 \mathrm{~kg}$ with a range of $1.25 \mathrm{~kg}$ to $4.30 \mathrm{~kg}$. $26 \%$ of neonates had a low birth weight (birth weight less than $2.5 \mathrm{~kg}$ ). All the sufficient group babies had a birth weight of more than $2.5 \mathrm{~kg}$.

TABLE 8: Only 7 babies in the study had an APGAR score less than 7 at 1 minute $(3.5 \%)$ and only 2 babies had an APGAR score less than 7 at 5 minutes (1\%). All babies $(100 \%)$ born to mothers with sufficient vitamin D levels had an APGAR score of more than 6 at both 1 and 5 minutes. The APGAR score at 1 minute and 5 minutes was similar for the deficient group versus the non-deficient group. There was no statistical correlation between the APGAR score and vitamin D levels at 1 $(p=0.3950)$ and 5 minutes $(p=0.7078)$.

TABLE 9: NICU admission was needed in $34 \%$ babies. Out of 68 NICU admissions 67 $(95.6 \%)$ were from the deficient group, whereas there was no NICU admission in babies born to mothers with sufficient vitamin D levels. The difference in NICU 
admission between the deficient and nondeficient group was statistically significant ( $p=\mathbf{0 . 0 3 8 4})$.

Table: 10 Most common indication for NICU admission were transient tachypnoea of newborn and respiratory distress syndrome $(27.9 \%$ vs $20.6 \%)$.

\section{Discussion}

Present study was conducted on 200 pregnant females who were admitted in the third trimester for delivery in the labor room. We assessed the vitamin D status of these females and correlated the same with the feto-maternal outcome of pregnancy.

It was observed that most of the subjects were deficient (Less than $20 \mathrm{ng} / \mathrm{ml}$ ) in terms of vitamin D levels $(187,93.50 \%)$. Only 8 (4\%) pregnant women had sufficient levels $(>30 \mathrm{ng} / \mathrm{ml})$ of vitamin D. In a study done by Prasad et $\mathrm{al}^{4}$ (2018) the deficient group included vitamin $\mathrm{D}$ deficient and insufficient levels $<30 \mathrm{ng} / \mathrm{ml}$ whereas study by Singh $\mathrm{N}$ et $\mathrm{al}^{6}$ (2015) included subjects with $<30 \mathrm{ng} / \mathrm{ml}$ as vitamin $\mathrm{D}$ deficient.

There was high was proportion of vitamin D deficient subjects having maternal complications was statistically significant as compared to the non-deficient group $(p=0.0109)$. For maternal complications to be labeled due to vitamin $\mathrm{D}$ deficiency, we need a bigger sufficient vitamin $\mathrm{D}$ sample size to compare with the deficient group. Among the deficient group out of all 97 subjects having maternal complication preterm delivery $(45,46.39 \%)$ was the most common complication seen in the study followed by anemia $(25,25.77 \%)$. Pregnant women with vitamin D deficiency had a higher prevalence of preterm birth, anemia, gestational diabetes mellitus, preeclampsia, hypothyroidism, and cholestasis. But the difference between the two groups was not significant statistically. In our study maternal complications were more in vitamin D deficient groups, in agreement with by Nageshu S et $\mathrm{al}^{6}$ (2016) and Prasad et $\mathrm{al}^{4}$ (2018).
Out of 75 women, $96 \%$ were from the deficient group. All the 8 pregnant women who had sufficient vitamin D levels delivered vaginally. In agreement to other studies conducted by S Arora et $\mathrm{al}^{7}$ (2018) and Prasad et $\mathrm{al}^{4}$ (2018), majority of the patients who underwent LSCS belonged to vitamin $\mathrm{D}$ deficient group. In a study done by Chauhan $\mathrm{N}$ et $\mathrm{al}^{6}$ (2018), the majority of patients undergoing LSCS had insufficient vitamin d levels (53.84\%).

There was no statistical correlation between the preterm birth and vitamin $\mathrm{D}$ levels $(p=0.8330)$ in present study. Palacios C et $\mathrm{al}^{9} \quad$ (2019) found that vitamin D supplementation alone made little or no difference in the risk of having a preterm birth $<37$ weeks' gestation.

The average birth weight was $2.72 \mathrm{~kg}$ with a range of $1.25 \mathrm{~kg}$ to $4.30 \mathrm{~kg}$. $26 \%$ of neonates had a low birth weight (birth weight less than $2.5 \mathrm{~kg}$ ). Our findings correlate with the findings of Prasad et al ${ }^{58}$ (2018) whereas other studies like by Nageshu S et $\mathrm{al}^{6}$ (2016) and Prasad et $\mathrm{al}^{4}$ (2018) had significant differences between the deficient and non-deficient groups.

The difference in NICU admission between the deficient and non-deficient group was statistically significant $(\mathbf{p}=\mathbf{0 . 0 3 8 4})$. The study done by Nageshu S et $\mathrm{al}^{6}{ }^{6}$ (2016) and Prasad et $\mathrm{al}^{4}$ (2018) showed that the correlation between deficient and nondeficient groups of babies with NICU admission was not statistically significant. A Study Done by Singh N et al ${ }^{5}$ (2015) showed NICU admissions were significantly reduced in women who were supplemented with vitamin D.

NICU admission was needed in $34 \%$ babies. Out of 68 NICU admissions 67 $(95.6 \%)$ were from the deficient group, whereas there was no NICU admission in babies born to mothers with sufficient vitamin D levels. The difference in NICU admission between the deficient and nondeficient group was statistically significant $(p=0.0384)$. 
The study done by Nageshu S et $\mathrm{al}^{6}$ (2016) and Prasad et $\mathrm{al}^{4}$ (2018) showed that the correlation between deficient and nondeficient groups of babies with NICU admission was not statistically significant. A Study Done by Singh N et al ${ }^{5}$ (2015) on vitamin D deficiency, its supplementation and effect on fetomaternal outcome during pregnancy. NICU admissions were significantly reduced in women who were supplemented with vitamin D.

\section{Conclusion}

Vitamin D deficiency is a major health burden in the population. Maternal complications, increased cesarean section rate and NICU admission were more associated with hypovitaminosis D but any causal relationship between vitamin D deficiency and maternal complications was not found in this study design. We conclude that larger randomized trials and higher quality clinical studies requiring bigger sample sizes of vitamin D sufficient females to compare and consolidate findings of the present study. We propose that vitamin D supplementation is simple and economical. So, we should incorporate vitamin $\mathrm{D}$ testing, increase its awareness and treat its deficiency in adolescence, preconceptional period or 1 st trimester to avoid maternal complications and poor fetal outcome.

\section{References}

1. Grant WB. An estimate of premature cancer mortality in the US due to inadequate doses of solar ultraviolet-B radiation. Cancer. 2002;94(6):18671875.

2. Sachan A, Gupta R, Das V, Agarwal A, Awasthi PK, Bhatia V. High prevalence of vitamin D deficiency among pregnant women and their newborns in northern India. Am J Clin Nutr. 2005;81(5):1060-4.

3. McCarty CA. Sunlight exposure assessment; can we accurately assess vitamin D exposure from sunlight questionnaires? AM J clin Nutr. 2008;87(4):1097-1101.

4. Prasad, Smita, Singh K, Swet N. Vitamin $\mathrm{D}$ in pregnancy and its correlation with feto maternal outcome. Int. J. Contemp. Med. 2018;5(1):1-5.

5. Singh N, Kumar D, Singh J, Chandanan A. A Study Of Vitamin D Deficiency, Its Supplementation And Effect On Fetomaternal Outcome During Pregnancy. Int J Reprod Contracept Obstet Gynecol. 2015;4(9):270-272.

6. Nageshu S, Krishna K, Krishna L, Bhat BS, Suma HR, Reddy S. A study of prevalence of Vitamin D deficiency among pregnant women and its impact on feto maternal outcome. Int J Reprod Contracept Obstet Gynecol. 2016;4(4):1174-1180.

7. Arora S, Goel P, Chawla D, Huria A, Arya A. Vitamin D status in mothers and their newborns and its association with pregnancy outcomes: experience from a tertiary Care Center in Northern India. J Obstet Gynaecol India. 2018;68(5):389-393.

8. Chauhan N, Pahuja N, Kalra V. Correlation of Vitamin D levels with feto-maternal outcome. Int J Reprod Contracept Obstet Gynecol. 2018;7(1):137-141.

9. Palacios C, Kostiuk LK, Peña-Rosas JP. Vitamin D supplementation for women during pregnancy. Cochrane Database Syst Rev. 2019;7(7):CD008873 